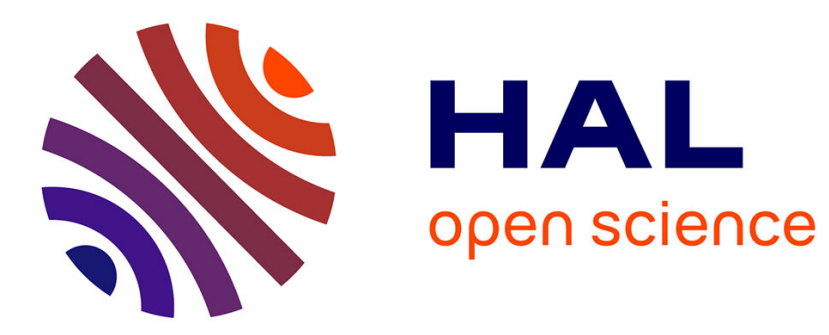

\title{
Real-time Kirchhoff migration for ultrasound imaging of the bone cortex
}

\author{
Guillaume Renaud, Jami L Johnson, Didier Cassereau
}

\section{To cite this version:}

Guillaume Renaud, Jami L Johnson, Didier Cassereau. Real-time Kirchhoff migration for ultrasound imaging of the bone cortex. SEG Technical Program Expanded Abstracts, 2018, pp.4797-4801. 10.1190/segam2018-2996779.1. hal-02355058

\section{HAL Id: hal-02355058 https://hal.science/hal-02355058}

Submitted on 8 Nov 2019

HAL is a multi-disciplinary open access archive for the deposit and dissemination of scientific research documents, whether they are published or not. The documents may come from teaching and research institutions in France or abroad, or from public or private research centers.
L'archive ouverte pluridisciplinaire $\mathbf{H A L}$, est destinée au dépôt et à la diffusion de documents scientifiques de niveau recherche, publiés ou non, émanant des établissements d'enseignement et de recherche français ou étrangers, des laboratoires publics ou privés. 


\section{Real-time Kirchhoff migration for ultrasound imaging of the bone cortex Guillaume Renaud*, Jami L. Johnson and Didier Cassereau, Laboratoire d'Imagerie Biomédicale - CNRS UMR7371- INSERM U1146 - Sorbonne Université - Paris, France}

\section{SUMMARY}

In this paper, we explore the feasibility of real-time ultrasound imaging of the cortex of a long bone. We show that it is possible in vivo with a conventional clinical ultrasound probe and a fully programmable ultrasound scanner. The ultrasound images are reconstructed using Kirchhoff migration and taking into account the elastic anisotropy of cortical bone tissue. An image rate of 1 image per second was achieved.

\section{INTRODUCTION}

Medical ultrasound imaging of a region containing a bone is highly similar to seismic imaging (Berkhout (1986)). Table 1 compares a selection of physical parameters for seismic imaging and medical ultrasound imaging. It is seen that, when normalized by the wavelength, the physical parameters have the same order of magnitude in seismic exploration and medical ultrasound in soft biological tissues. Nonetheless, the ratio between the wavelength and the characteristic size of heterogeneities is much smaller in medical ultrasound, which causes diffuse scattering to be much stronger than in seismic signals. It is also worth noticing that attenuation is significantly higher in cortical bone.

\begin{tabular}{|c|c|c|}
\hline & $\begin{array}{c}\text { Seismic } \\
\text { exploration }\end{array}$ & $\begin{array}{c}\text { Medical ultrasound } \\
\text { (soft tissues/cortical bone })\end{array}$ \\
\hline Wave-speed & $3000 \mathrm{~m} \cdot \mathrm{s}^{-1}$ & $1540 / 3500 \mathrm{~m} \cdot \mathrm{s}^{-1}$ \\
\hline Frequency & $30 \mathrm{~Hz}$ & $5 \mathrm{MHz}$ \\
\hline Wavelength & $0.1 \mathrm{~km}$ & $0.3 / 0.7 \mathrm{~mm}$ \\
\hline $\begin{array}{c}\text { Investigated } \\
\text { depth }\end{array}$ & $\begin{array}{c}10 \mathrm{~km} \\
(100 \text { wavelengths })\end{array}$ & $\begin{array}{c}150 \mathrm{~mm} \text { in soft tissues } \\
(500 \text { wavelengths })\end{array}$ \\
\hline $\begin{array}{c}\text { Attenuation } \\
\text { dB.wavelength }\end{array}$ & $\begin{array}{c}0.1 / 5 \\
\text { dB.wavelength }\end{array}$ \\
\hline $\begin{array}{c}\text { Diffuse } \\
\text { scattering }\end{array}$ & $\begin{array}{c}\text { weak } \\
(\ll \text { specular } \\
\text { reflection })\end{array}$ & $\begin{array}{c}\text { strong } \\
(\approx \text { specular } \\
\text { reflection })\end{array}$ \\
\hline
\end{tabular}

Table 1: Comparison of a selection of physical parameters for seismic imaging and medical ultrasound imaging.

Current clinical ultrasound scanners fail to image the interior structure of bones, because a major assumption is made to achieve real-time ultrasound imaging with up to 50 images per second. Indeed a clinical ultrasound scanner assumes a simplified medium with a uniform wave-speed (usually $1540 \mathrm{~m} / \mathrm{s}$, an average value in soft biological tissues). This assumption is acceptable in soft tissues because the difference between the average value and the true speed of sound is at most $\pm 10 \%$ (Szabo (2014)). However this assumption does not hold for cortical bone tissue that forms the cortex (outer shell) of bones. The speed of sound in cortical bone is much larger (2800 to 4200 $\mathrm{m} / \mathrm{s}$, Granke et al. (2011)) than that in soft tissues (1400-1700 $\mathrm{m} / \mathrm{s}$, Shung (2015)), which leads to significant refraction when an ultrasound wave traverses an interface between soft tissue and cortical bone.

It is largely thought that clinical ultrasound scanners fail to image bone because i) ultrasound attenuation in cortical bone is high (close to $10 \mathrm{~dB} / \mathrm{cm} / \mathrm{MHz}$, Zheng et al. (2007); Shung (2015)) and ii) energy transmission through an interface between soft tissue and cortical bone is weak (large acoustic impedance mismatch). Although these effects play their part, we demonstrate in this work that the main issue is refraction. Here we apply Kirchhoff migration and take into account the elastic anisotropy of cortical bone tissue to reconstruct an image of the bone cortex of a long bone.

\section{IMAGE RECONSTRUCTION}

For data acquisition, we employed a scheme where every element in the probe array subsequently broadcasts a quasi-spherical diverging wavefront, while all the elements of the array record the backscattered echo signals. This acquisition procedure is very similar to that used in seismic exploration. For image reconstruction, we used Kirchhoff migration, which is called the delay-and-sum method in medical ultrasound (Szabo (2014)). The amplitude in the image $I(P)$ at point $\mathrm{P}$ is given by:

$$
I(P)=\sum_{i=1}^{M} \sum_{j=1}^{N} W(P, i, j) \times D\left[t=t_{T}(i, P)+t_{R}(j, P), i, j\right] .
$$

$M$ and $N$ are the number of transmitting elements and receiving elements, respectively. $D\left[t=t_{T}(i, P)+t_{R}(j, P), i, j\right]$ is the recorded data value when element $i$ transmits and element $j$ records, evaluated at the time $t=t_{T}(i, P)+t_{R}(j, P)$ and weighted by an appropriate factor $W(P, i, j) . W(P, i, j)=1$ if the emerging angles from the transmit and receive elements $i$ and $j$ to point $\mathrm{P}$ are smaller than acceptance angle (Nikolov et al. (2010)), otherwise $W(P, i, j)=0$.

The calculation of the travel time from an element of the probe array to an image point was performed with a bending ray tracing technique which is extensively used by seismologists (Waltham (1988)). The law of refraction (Snell's law) is imposed at all interfaces but one, and the angle of the emerging ray at the element is varied until a minimum travel time is obtained (Fermat's principle). In conventional image reconstruction, the calculation of the round-trip travel times reduces to a simple geometry problem since an ultrasound ray from an element of the probe array to an image point is straight.

For Kirchhoff migration, image reconstruction consists of two steps. The entire region of interest is first assumed to be homo- 


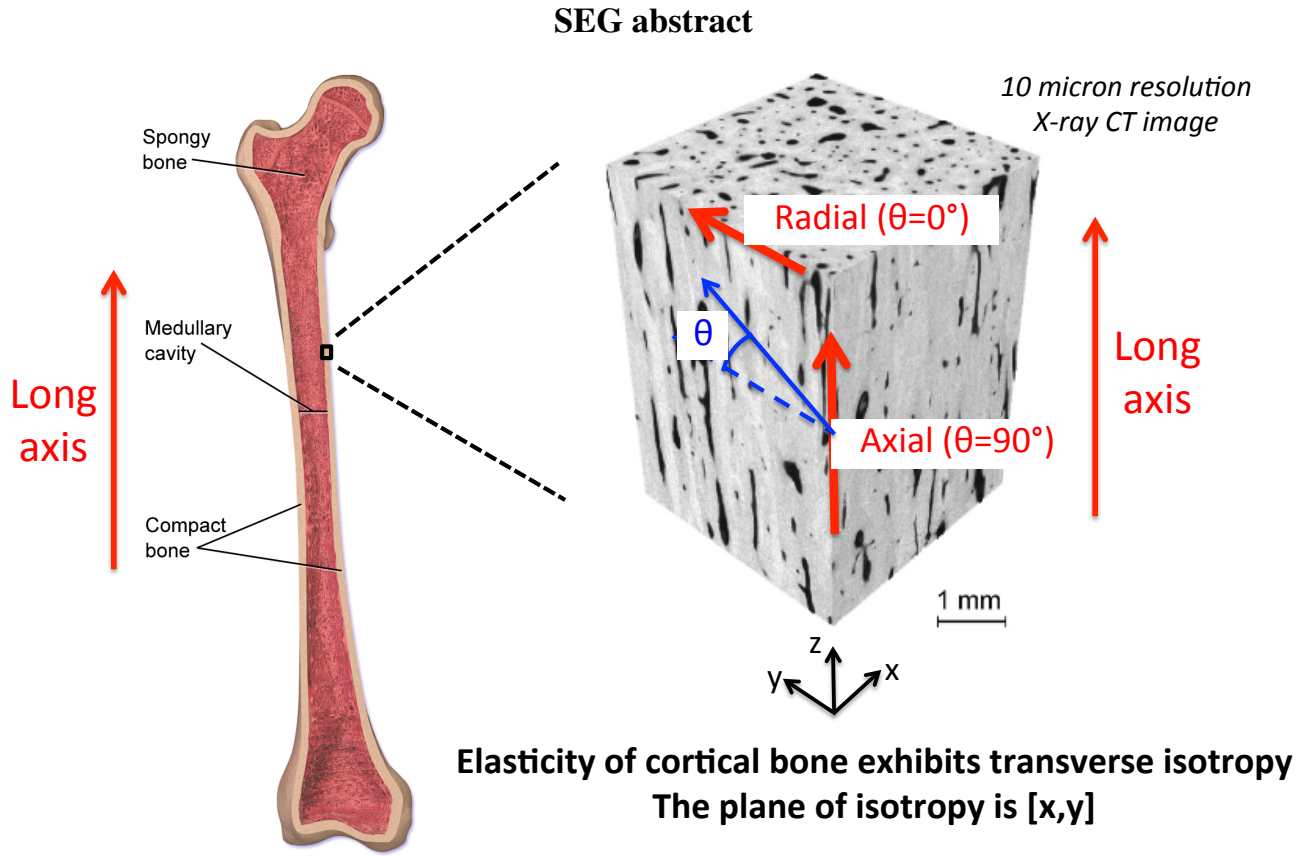

Figure 1: Enlargement of a small volume of cortical bone from the cortex of a long bone, as observed with synchrotron radiation X-ray computed tomography (adapted from Granke et al. (2011)).

geneous soft tissues. In this image, only the region between the ultrasound probe and the outer surface of the bone (cutaneous tissue) is correctly reconstructed. Then the outer surface of the bone is automatically segmented and fitted with a parabola. Next, the region that is deeper than the outer surface of the bone, i.e. the bone cortex, is reconstructed. Finally the two image parts are spliced, log-compressed and displayed with a dynamic range of $40 \mathrm{~dB}$.

\section{ANISOTROPY OF THE RAY VELOCITY IN CORTICAL BONE}

Ex vivo studies have demonstrated that the elasticity of human cortical bone is well described by a model of transverse isotropy (Granke et al. (2011); Bernard et al. (2016); Cai et al. (2017)). The elastic anisotropy of cortical bone has two origins: the cortical porosity (Haversian canals, see Figure 1) and micrometer-scale structure of the mineralized collagen matrix. For the central part of a long bone, the plane of isotropy is normal to the axis of the long bone. The compressional wavespeed is $20 \%$ higher in a direction parallel to the axis of a long bone than in a direction normal to the axis of the long bone (Granke et al. (2011)).

We used a model of weak elastic anisotropy proposed by seismologists (Thomsen (1986)). The group velocity (ray velocity) of the compressional wave in cortical bone $V_{\text {bone }}$ is modeled with the following equation:

$V_{\text {bone }}=V_{\text {axial }}-\left(V_{\text {axial }}-V_{\text {radial }}\right)\left[\beta \sin ^{2}(\theta) \cos ^{2}(\theta)+\cos ^{4}(\theta)\right]$.
$V_{\text {radial }}$ is the compressional wave-speed in the plane of isotropy. $V_{\text {axial }}$ is the compressional wave-speed in the direction of the axis of the long bone. $\beta$ is an anisotropy form parameter. $\theta$ is the angle between the ultrasound ray in cortical bone and the normal to the interface between soft tissue and bone.

The group velocity was computed using ex vivo measurements of the elastic constants human cortical bone (Granke et al. (2011); Bernard et al. (2016); Cai et al. (2017)). In vivo imaging is performed on a healthy volunteer, therefore average values of the elastic constants for low-porosity human cortical bone (mass density $=1900 \mathrm{~kg} / \mathrm{m}^{3}$ ) were used to calculate the group velocity for a quasi P-wave ; $C_{11}=20 \mathrm{GPa}, C_{33}=30$ $\mathrm{GPa}, C_{44}=6 \mathrm{GPa}$ and $C_{13}=12 \mathrm{GPa}$. We obtain $V_{\text {axial }}=$ $3970 \mathrm{~m} / \mathrm{s}, V_{\text {radial }}=3240 \mathrm{~m} / \mathrm{s}$ and $\beta=1.37$. Figure 2 depicts the dependence of the group velocity (ray velocity) in cortical bone on the group angle (ray angle) $\theta$, as calculated with exact elastic anisotropy (Thomsen (1986)) and as computed with the weak anisotropy model (Equation 2). It is seen that the model of weak anisotropy provides a good approximation.

\section{IN VIVO RESULTS}

Ultrasound recordings were conducted at the radius bone (forearm) of a healthy volunteer recruited from the laboratory staff. The ultrasound probe was aligned with the long axis of the bone in order to produce an image in the longitudinal view. The inter-element pulse-echo signals were recorded using a fully programmable ultrasound system (Vantage 64LE, Verasonics Inc., Redmond, WA, USA) equipped with a $5 \mathrm{MHz}$ linear array transducer (L7-4 ATL, Bothell, WA, USA; pitch $0.298 \mathrm{~mm}, 128$ elements). Figure 3 shows two ultrasound images, obtained with conventional reconstruction that assumes a medium with uniform wave-speed and with Kirchhoff migra- 
SEG abstract

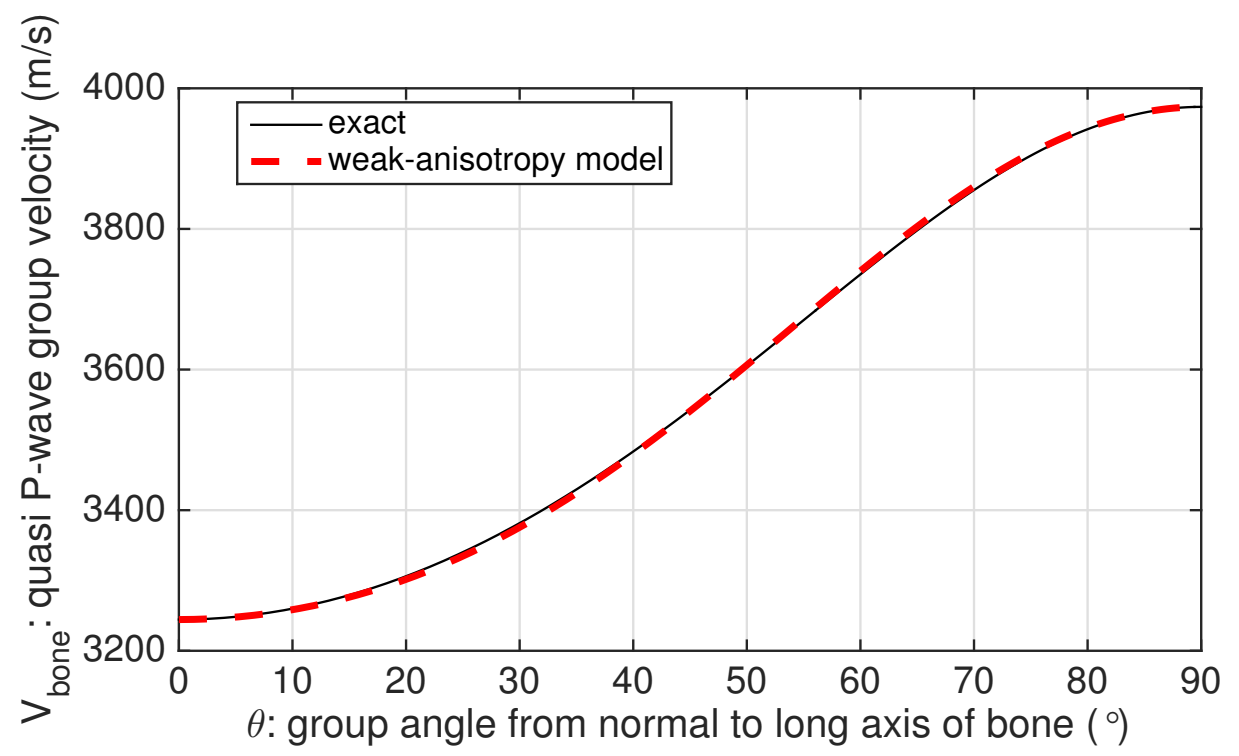

Figure 2: Dependence of the group velocity of a quasi-compressional wave on the direction of propagation in cortical bone, as calculated with exact elastic anisotropy and with the model of weak elastic anisotropy (Equation 2).

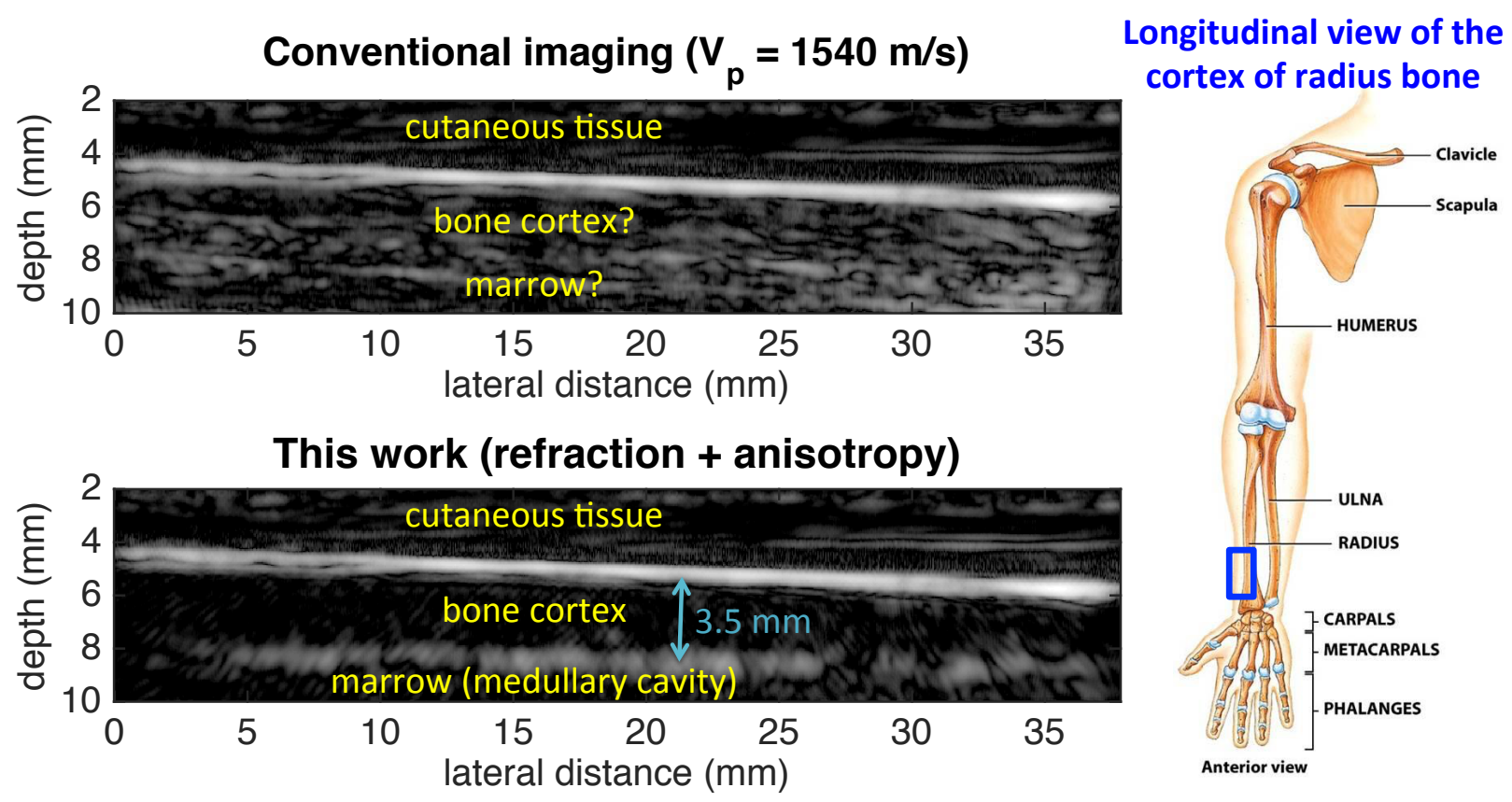

Figure 3: Ultrasound image of the bone cortex obtained at the radius (forearm) of a healthy volunteer with conventional image reconstruction (top panel) and Kirchhoff migration (bottom panel) that takes into account refraction and elastic anisotropy. 


\section{SEG abstract}

tion.

While it is very difficult to identify the inner surface of the bone cortex (interface between cortical bone and marrow) in the conventionally reconstructed image, it is clearly visible in the image obtained with Kirchhoff migration. Unlike conventional image reconstruction in medical ultrasound, Kirchhoff migration considers refraction at the outer surface of the bone and elastic anisotropy in cortical bone.

In the image obtained with Kirchhoff migration, we measure a bone cortex thickness of $3.5 \mathrm{~mm}$, which is expected for a healthy volunteer at this location of the radius bone (Vallet et al. (2016)).

\section{DISCUSSION AND CONCLUSION}

In this paper we showed that if the physics is properly addressed, the bone cortex of a long bone can be imaged in vivo with ultrasound using a conventional clinical probe operating at a center frequency of $5 \mathrm{MHz}$. Refraction and elastic anisotropy of cortical bone must be considered in order to reconstruct an accurate image of the bone cortex. We chose Kirchhoff migration for real-time imaging of bone because it is a fast and flexible migration method. CPU parallel computing allows real-time ultrasound imaging with a frame rate of 1 image per second.

Future work will evaluate the feasibility of imaging the complete cross-section image of a bone. One of the main challenges to achieve this is the reduction of multiple reflections. They are produced by a reflection on the surface of the probe and two reflections on bone interfaces (see Figure 4). Their travel time is close to that of the primary reflections on the second inner surface and the second outer surface in a long bone. Therefore reduction of multiple reflections is required to reconstruct the complete cross-section image of a bone.

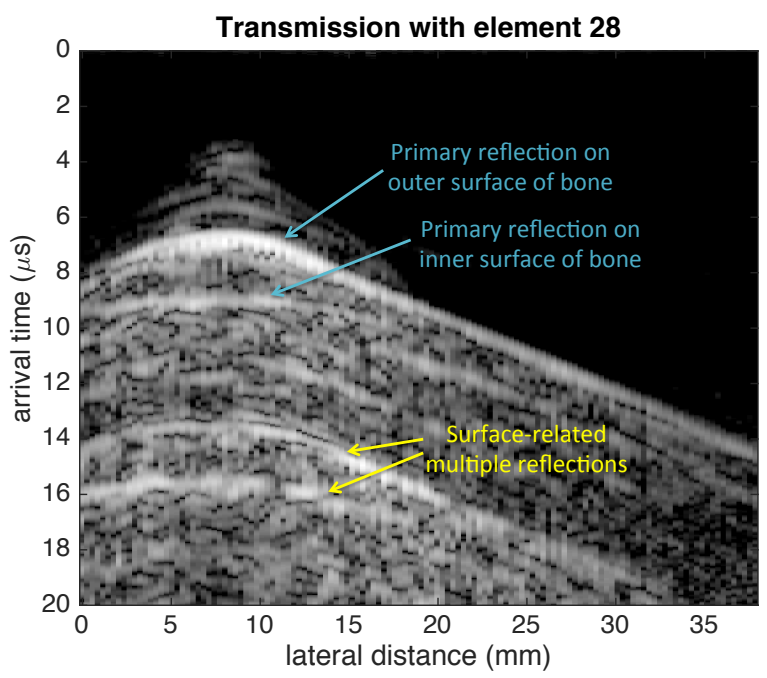

Figure 4: Recording by all elements when element 28 transmits. Surface-related multiple reflections are clearly visible.

\section{ACKNOWLEDGMENTS}

This work has been funded by Émergence Sorbonne Université (FUIBCA grant). 